Journal of Psychiatric \& Mental Health Nursing

Volume 8 Page 173 - April 2001

doi:10.1046/j.1365-2850.2001.0365a.x

Volume 8 Issue 2

\title{
Commentary
}

\section{Psychiatric nursing and organizational power: rescuing the hidden dynamic}

Alec Grant

Reflecting recent discussions on the psychiatric nursing mailbase, a selective overview of the psychiatric nursing literature reveals familiar ways of conceptualizing power. These include the subordinate role of nurses to medical decision making, and the ability of psychiatric nurses to empower otherwise disempowered patients (Barker 1999, Clarke 1999). Abuses of power are also described, such as the physical and sexual abuse endemic on mixed psychiatric wards (Newton 1996). However, perhaps characteristic of the profession's relative lack of interest in the organizational literature, no mention is made of the power inherent in the operating style of the settings within which nurses work. This is both surprising and ironic, given the organizational literature emerging over the last 25 years documenting the way bureaucracies shape professional identity (Georgiades \& Phillimore 1975, Pfeffer 1981, Gilbert 1990, Morgan 1997).

The aim of this paper is to clarify the hidden dynamic of structural organizational power (Pfeffer 1981) and related concepts. To illustrate its main elements and discuss its role in the shaping of psychiatric nursing identity, I will firstly draw on my own PhD research (Duncan-Grant 1999). Structural power served as the 'best analytical fit' to account for the ways in which organizational factors shaped the experience and practice of clinical supervision among psychiatric nurses. I will go on to argue that this conceptual framework also speaks to broader aspects of psychiatric nursing professional identity.

\section{Structural organizational power and related concepts}

According to Pfeffer (1981), structural power is built into the interpersonal and material structure of organizations, and thus - by definition - is most effective when its exercise is least apparent to organizational members. Familiar and repeated procedures (or, 'the way things are done around here') receive a rational justification over time, and contribute towards repeated patterns of expectation and influence. Pfeffer terms this phenomenon procedural rationality: the phenomenon of custom and practice-driven procedures becoming institutionalized over time as implicit norms imbued with authority. 
The influence of this authority is constant and is reflected in the interpersonal relationships of the organization into which its members are socialized. Pockets of dissent are contained and minimized within a kind of overarching 'common sense', which - in the case of psychiatric nurses - may often be disempowering. The established rules and norms of organizations generally win out and are taken for granted as common sense, needing little justification.

In my research, organizational patterns of expectation influencing the uptake and practice of clinical supervision could be seen in problems around ownership of the concept. Deference to rank was reflected in the assumption of operational managers that the Trust Board were the group responsible for the inception of clinical supervision in the directorate studied. Rank awareness also influenced nursing staff, in either waiting until the organization provided them with clinical supervision or in the belief that clinical supervision should be provided by their line manager. In keeping with organizational custom and practice, it is understandable that this method of the delivery of clinical supervision would be the one considered most appropriate by the Trust.

The strategic and conceptual literature on clinical supervision influenced nurses' views of themselves as accountable for seeking their own supervision, and this was reflected in frequent attempts to persuade their line manager to provide it. The repeated failure of those attempts illustrate the contradictions between the prescriptions of the literature and local organizational custom and practice. The need to honour clinical supervision appointments usually conflicted with other activities viewed as more important.

Key elements in the maintenance of structural organizational power include the influence of emotional management on organizational survival (Fineman 1993) and the interpersonal self-presentation rules to which all of us conform (Goffman 1969). Regarding emotional management, organizations develop and sanction 'feeling rules'. These are reflected, materially, in areas where it is safe or unsafe to express emotion. Ironically, given clinical supervision in nursing's contemporary celebration of open disclosure (Butterworth et al. 1997), authentic displays of emotion were generally discouraged in clinical supervision sessions, while, in contrast, many research participants appeared to feel safe enough to talk about their supervision horror stories in interviews with me.

The contradiction between the prescriptions of the clinical supervision in nursing and mental health nursing literature and local organizational norms thus influenced the way individuals managed their emotions. In further illustration of this point, there existed an implicit contract, within which supervisees needed to be seen to be coping with their job. In related terms, in-house line supervi-sion by their managers was the rule rather than the exception. This meant that the potential for the supervision agenda imposed by supervisors to be punitive and critical, and for confidentiality breaches to occur, was increased. It was thus clearly not in the interests of supervisees to display emotional vulnerability within supervision sessions. 
Turning to the importance of self-presentation in organizations, supervisee and supervisor often had shared histories in the mental health directorate prior to starting their supervision relationship. The fact that organizational relationships frequently preceded and informed clinical supervision relationships influenced the form of face-saving and impression-management strategies. A major issue emerging was that it seemed, in the main, that amicable organizational relationships could only be maintained at the expense of effective clinical supervision relationships.

Given the above, there is a clear conceptual problem with clinical supervision in the nursing and mental health nursing literature. In treating the concept in a one-dimensional, decontextual way, nurses are exhorted to embrace clinical supervision while the probable local difficulties involved in this task are either effaced or played down. Quite simply, organizational factors restrict the success of psychiatric nurses' attempts to live up to the prescriptions of the clinical supervision literature. By implication, this strongly suggests a need to scrutinize some of the claims of contemporary writers on what psychiatric nursing is or should be about, with regard to the degree to which they take account of the nature of organizational power.

I have chosen to limit my discussion mainly, but not exclusively, to the work of Barker and Clarke. I do so because of my affection for, and familiarity with, their writing, which has been pivotal in the development of my own work. After a brief critical discussion of their relative contributions, I will go on to argue that neither pay sufficient attention to the importance of organizational factors in the development of professional identity, effectively undermining their claims.

\section{Barker's new nurse spiritualism}

Barker (1997) regards psychiatric nurses as spiritual healers, distinguishing their contribution to psychiatric and mental health care from that of other professions. How nurses actually do this is, for Barker, 'the question I am least confident about asking'. The moral and ethical day-to-day tasks of psychiatric nursing are described as key mediating factors (Barker 1999). Barker's morality is based upon the standards of behaviour governing what is considered appropriate by the profession and by society, while ethical practice is reflected in how such standards are monitored.

Complementing his spiritual position, Barker (1999) displays a humanisticexistentialist view of psychiatric nursing, in at least three senses. First, from a neo-Rogerian perspective, he claims that the proper focus of psychiatric nursing is in helping individuals grow and develop within the limits of their personal and environmental circumstances. Secondly, he argues that psychiatric nurses are necessarily always making ethical choices, based upon professional values underpinning their attitudes. Finally, acknowledging, with Clarke, that such decision making is constrained by the medically led hierarchy that nurses find themselves in, he exhorts them - in the interests of professionalizing - to rise above such constraints. 
The above claims are seductive. However, from the perspective of the role, impact and form of structural power argued earlier, both generic and specialist psychiatric nurses may in reality often find it very difficult to challenge and overcome the invisible exercise of organizational power, of which ongoing medical leadership is simply an element. Specifically, what nurses do at any one time, as opposed to what they might like to do (for some at least, influenced by Barker's writing), is likely to generally conform to that which has been established in local custom and practice, and related patterns of expectation and influence.

Self-presentation and emotional management factors will contribute to this process, influencing the public behaviour of nurses in the maintenance of selfesteem. As a general principle, despite frequent exceptions to the rule, nurses - like all of us - want to get on with their colleagues and be seen to be coping with their jobs. Specifically, this is likely to result in tensions between what they feel privately and express publicly, and strategies to help them maintain good face in the organization. Finally, the gap between their postqualification idealism and the values and behaviours they need to develop to survive in the work settings they find themselves in will gradually reduce (Georgiades \& Phillimore 1975).

If, however, for the sake of argument, it were possible for the majority of nurses to rise above organizational procedural rationality in decision making and choice, then it is important to consider the preparation of psychiatric nurses for this ethical endeavour. In keeping with his style of refusing to articulate the fine detail of other aspects of his case, Barker (1999) side-steps this problem in his zen-influenced assertion that training individuals in ethical practice is a contradiction in terms.

With a reading of Barker as a neo-Rogerian, if self-awareness is considered an essential element of ethical practice, there are important educational and organizational implications emerging from this. To take a local example, there's a certain poverty in the emphasis on self-awareness for student psychiatric nurses as a year-one modular topic only at the University of Brighton. This is compounded by the fact that the theoretical background for this is, in large part, based on the kind of Rogerian-like strands which Barker displays in his writing (Barker 1999, Clarke 1999).

It seems plausible to argue that Rogerian influences pervade curricula and group-think at least in part because of their function as a kind of comforting porridge (L. Clarke, personal communication). This seeps through module development and educational delivery, serving to insulate against the realworld organizational constraining and shaping factors that nurses will, in reality, find themselves in both during and after training. Few would deny the often positive influence of Rogerian principles for the human caring services over the last few decades. However, there is a clear danger in its teaching and reception by students as a totalitarian psychotherapeutic world-view, because of a lack of consideration of qualifying, balancing and sometimes contradictory psychotherapeutic and social-psychological factors (Clarke 1999). A facile, non-critical acceptance of Rogerian and neo-Rogerian 
principles turns the approach into a minimally demanding fairy tale for grownups. Little consideration is given to the actual form and exercise of organizational power in limiting the effectiveness of such interventions and to related interpersonal factors undermining them.

Further, an ethically driven self-awareness that is at least implicitly associated with Rogerian principles merits close and critical empirical scrutiny. In spite of, over decades, a consistent lack of evidence demonstrating the sufficiency of the Rogerian approach for personal helping and change (Shapiro 1969, Dallard 1999), the appeal of Rogerian-derived interventions for counselling, psychotherapy and psychiatric nursing continues to thrive. This appeal arguably lies in its comfortingly simplistic and de-contextual presentation: professional backgrounds aside, all you need is a facilitator-listener armed with a minimal amount of skills, knowledge and theory, and a client or patient. Structural organizational constraints and related interpersonal factors which make the approach problematic are treated (or ignored) as superfluous.

\section{Clarke's new nurse fundamentalism}

Clarke (1999), like Barker, wants to clarify a 'proper focus' for psychiatric nursing. However, in criticism of Barker's overall thesis, he argues that humanistic psychiatric nursing practitioners are, in reality, in the minority, with the majority of psychiatric nursing practice influenced by medical decision making. He reminds us that the working majority of psychiatric nurses continue to practice in institutional settings, asserting that they are content to give out drugs and assist in electroconvulsive therapy. In keeping with the principles and examples of structural power outlined above, he is correct in stating that what most psychiatric nurses do, in other words, is prescribed by organizational expectation and influence.

Current writing within the Royal College of Nursing continuing professional development framework, and observations of the dialogue on the psychiatric nursing mailbase, supports Clarke's views. In reviewing contemporary treatments for the problem, Parsons (1999/2000) concludes that the 'role of the nurse in working with someone with depression is essentially that of support and monitoring, working with the depressed person to help him or her progress towards recovery'. With regard to what the nurse actually does to aid this, Parson's words simultaneously echo both Barker's neo-Rogerian position and Clarke's views on nurses' medical subservience, while, ironically, rubber stamping organizational custom and practice. To quote from Parsons, 'The importance of simply being with the depressed person and valuing their experience, at the same time as supporting medical treatment and interventions, cannot be over-emphasised.'

Much of the discussion space in the psychiatric nursing mailbase in 1999 was taken up with issues around day-to-day practice: handovers, close observation, and, from time to time, complaints about the power differential between doctors and nurses. In Clarke's terms, supporting Pfeffer's views on structural organizational power, the source of the socialization for this dialogue clearly seems to be in the reality of working within institutional 
settings. However, despite developing a social-psychological dimension to his case to a greater extent than Barker, Clarke's organizational polemic is flawed in the area of what psychiatric nurses should do in their day-to-day practice.

He argues that the proper focus of psychiatric nursing is around 'ordinary decency', psychiatric nurses relating to their patients pragmatically in terms of what they need at any particular point in time. 'Ordinary decency' is a term defined negatively - the proper location for psychiatric nursing lying somewhere in the middle of two poles, with transpersonal and spiritual approaches at one end and specialist therapies at the other. Clarke fails, however, to clarify what the concept might amount to, in other than negative terms.

A major problem emerges from this polemic: psychiatric nurses are exhorted to jettison unnecessary and superfluous theories and models which fail to capture the real demands of their largely practical task. Doing so will supposedly leave nurse-patient relationships free of any external mediating influences. However, in line with my criticism of Barker above, it is arguably likely that the organizational context in which nurses work will socialize them to a common-sense justification for doing what they do. Because of this, aspirations and claims to 'ordinary decency' may simply amount to rationalizations made within, and to justify, local custom and practice. All staff working in bureaucratic environments operate according to pre-established material and interpersonal rules which, necessarily, influence nurse-patient relationships. To cite a specific example, it is probable that many otherwise decent nurses are currently engaged in subtle but effective coercion of informal patients to accept treatment in inpatient settings (Lindow 1993).

\section{Conclusion}

After giving a very brief overview of the form of the dialogue around power in some of the litera-ture and electronic discussions among psychiatric nurses, I used examples from my own research to illustrate Pfeffer's organizational structural power concept. I argued that this is useful in accounting for some of the ways in which aspects of psychiatric nursing identity are shaped by the work settings within which psychiatric nurses are employed.

Turning to contemporary visions about what psychiatric nursing is or should be about, I went on to propose that neither Barker nor Clarke take sufficient account of those organizational operating factors to make their work coherent, and that this is not helped by their refusal to spell out what doing nursing would be like within their respective visions. Barker's neo-Rogerianism seems to have implications for an educational context which colludes in a view of psychiatric nursing practice stripped of its real world organizational shaping context. Clarke, while going further than Barker in this area, still ultimately produces a confused argument. While clearly acknowledging that nursing identity is mediated by structural factors, he calls for a form of psychiatric nursing practice amounting to unmediated 'ordinary decency'. 
A possible objection to the structural power framework I have proposed is that it does not allow for progress within psychiatric nursing, or for psychiatric nurses to shape their own identities. It is certainly the case that generic and specialist psychiatric nursing advanced considerably in the last century (Nolan 1993, Newell \& Gournay 1994). This points to the role of positive conceptions of power in bringing about change (Foucault 1978, Fee 2000). However, in spite of this, the structural power concept clearly speaks to the pace of change in the gap between prescription and organizational custom and practice. While relatively free to progress and increasingly professionalize over time, psychiatric nursing identity generally remains, in large part, a function of the material and interpersonal operating principles of the work settings in which nurses are employed.

\section{References}

Barker P.J. (1997) Assessment in Psychiatric and Mental Health Nursing: In Search of the Whole Person. Stanley Thorne, Cheltenham

Barker P. (1999) The Philosophy and Practice of Psychiatric Nursing. Churchill Livingston, London

Butterworth T., Carson J., White E., Jeacock J., Clements A., Bishop V. (1997) It Is Good to Talk. an Evaluation Study in England and Scotland. School of Nursing, Midwifery and Health Visiting, University of Manchester, Manchester.

Clarke L. (1999) Challenging Ideas in Psychiatric Nursing. Routledge, London

Dallard D. (1999) What does counselling do? A critical re-examination of Rogers' core conditions. Mental Health Care 21, 383-385.

Duncan-Grant A.J. (1999) Clinical Supervision Activity Among Mental Health Nurses: a Critical Organizational Ethnography. Unpublished PhD Thesis, University of Brighton, Brighton

Fee D. (2000) The broken dialogue: mental illness as discourse and experience. In: Pathology and the Postmodern (ed. Fee D.), pp. 1-17. Sage, London

Fineman S., ed. (1993) Emotion in Organizations. Sage, London

Foucault M. (1978) Power/Knowledge: Selected Interviews and Other Writings. Pantheon, New York

Georgiades N.J. \& Phillimore L. (1975) The myth of the hero-innovator and alternative strategies for organizational change. In: Behaviour Modification with the Severely Retarded (eds Kiernan C.C. \& Woodford F.P.), pp. 313319. Associated Scientific Publishers, London. 
Gilbert P. (1990) Organisations, Stress and the Evolution of Group Living. Paper presented at the British Association of Behavioural Psychotherapy annual conference. UMIST, Manchester

Goffman E. (1969) The Presentation of Self in Everyday Life. Pelican Books, Reading.

Lindow V. (1993) A service user's view. In: Mental Health Nursing: From First Principles to Professional Practice (eds Wright H. \& Giddey M.). Stanley Thornes, Gateshead

Newell R. \& Gournay K. (1994) British nurses in behavioural psychotherapy: a 20 year follow-up. Journal of Advanced Nursing 20, 5 3-60.

Newton S.A. (1996) Women and mental health nursing. In: Perspectives in Mental Health Nursing (eds Sanford T. \& Gournay K.). Balliere Tindall, London

Nolan P.A. (1993) A History of Mental Health Nursing. Chapman \& Hall, London

Parsons S. (1999/2000) Working with depression. Mental Health Practice 3, 32-35.

Pfeffer J. (1981) Power in Organizations. Pitman, Marshfield, MA

Shapiro D. (1969) Warmth and genuineness in psychotherapy. British Journal of Clinical Psychology 8, 350-361. 